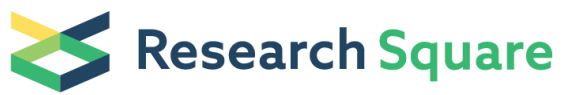 \\ Preprints are preliminary reports that have not undergone peer review. \\ They should not be considered conclusive, used to inform clinical practice, or referenced by the media as validated information.
}

\section{Adverse Neonatal Birth Outcomes Among Adolescent Pregnancies in Kampala, Uganda Between 2015 -2018}

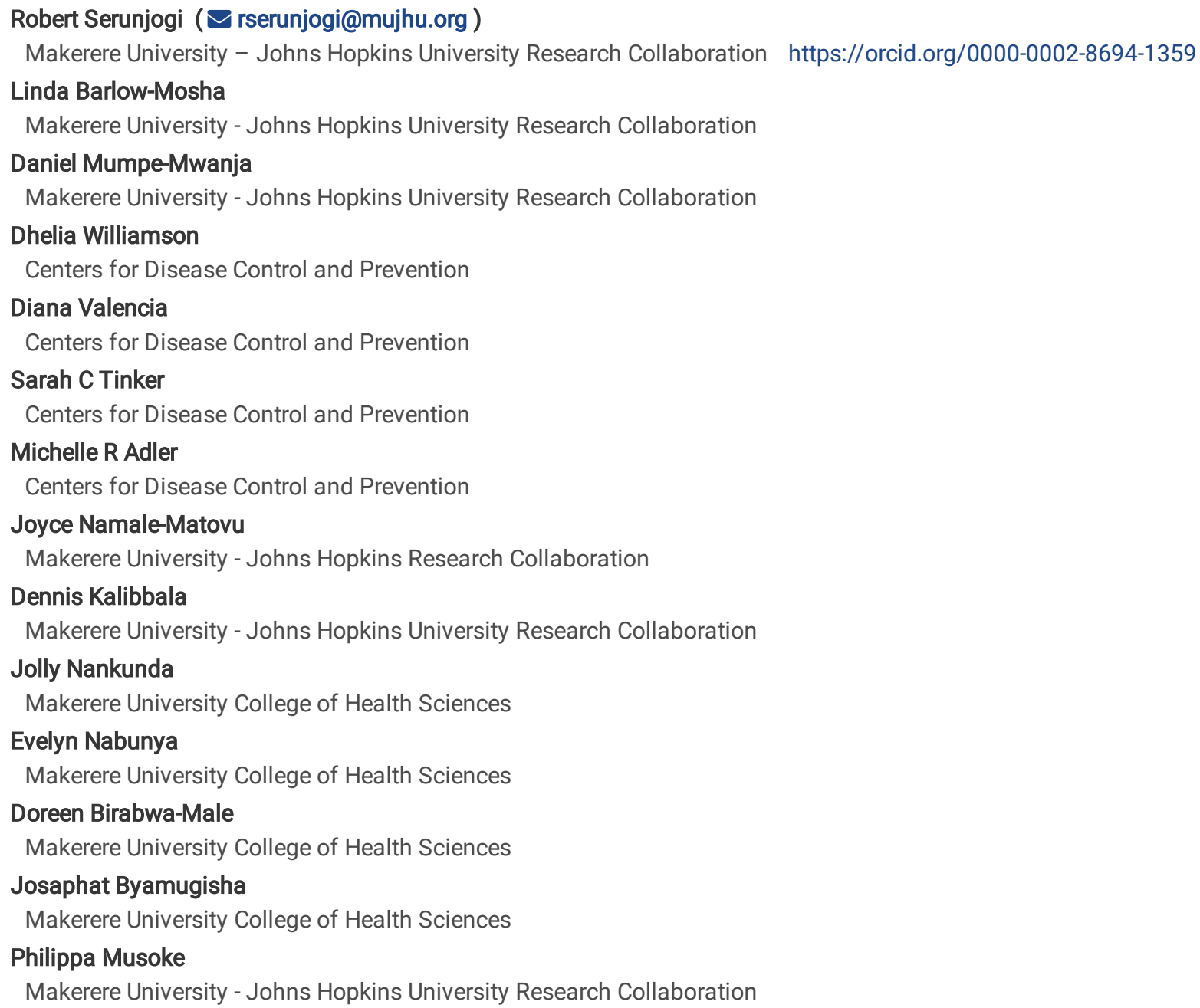

\section{Research}

Keywords: Adolescent, birth outcomes, birth defects, gastroschisis, low birthweight, early neonatal death, preterm, Hospital-based surveillance, Sub-Saharan Africa, Uganda

Posted Date: September 16th, 2020

DOI: https://doi.org/10.21203/rs.3.rs-74065/v1

License: (c) This work is licensed under a Creative Commons Attribution 4.0 International License. Read Full License 


\section{Abstract}

Background: Uganda has one of the highest adolescent pregnancy rates in sub-Saharan Africa. We compared the risk of adverse birth outcomes between adolescents (age 12-19 years) and older mothers (age 20-34 years) in four urban hospitals.

Methods: Maternal demographics, HIV status, and birth outcomes of all live births, stillbirths, and spontaneous abortions delivered from August 2015 to December 2018 were extracted from a hospital-based birth defects surveillance database. Differences in the distributions of maternal and infant characteristics by maternal age groups were tested with Pearson's chi-square. Adjusted odds ratios (aORs) and 95\% Confidence Intervals $(\mathrm{Cl})$ were calculated using logistic regression to compare the prevalence of adverse birth outcomes among adolescents to older mothers.

Results: A total of 100,189 births were analyzed, with $11.1 \%$ among adolescent mothers and $89.0 \%$ among older mothers. A significantly higher proportion of HIV-infected adolescents were not initiated on antiretroviral therapy by the time of delivery compared to HIV-infected older mothers ( $8.8 \%$ vs $4.4 \%, \mathrm{p}<0.001)$. Adolescent mothers had an increased risk of preterm delivery (aOR: 1.14; Cl: 1.06-1.23), low birth weight (aOR: 1.46; Cl: 1.34-1.59), and early neonatal deaths (aOR: 1.58; Cl: 1.23-2.02). Newborns of adolescent mothers had an increased risk of major external birth defects (aOR: 1.33; Cl: 1.02-1.76), specifically, gastroschisis (aOR: 3.20; Cl: 1.12-9.13) compared to older mothers.

Conclusions: This study found that adolescent mothers had an increased risk for several adverse birth outcomes compared to older mothers, similar to findings in the region and globally. Interventions are needed to improve birth outcomes in this vulnerable population.

\section{Plain English Summary}

Adolescent pregnancies are a global problem occurring in high-, middle-, and low-income countries with Uganda having one of the highest adolescent pregnancy rates in sub-Saharan Africa. We compared the risk of adverse birth outcomes between adolescents (age 12-19 years) and older mothers (age 20-34 years) in four urban hospitals.

All informative births, including live births, stillbirths, and spontaneous abortions; regardless of gestational age, delivered at four selected hospitals in Kampala from August 2015 to December 2018 were examined. Demographic data were obtained by midwives through maternal interviews and review of hospital patient notes.

Of the 100,189 births, $11.1 \%$ were among adolescent mothers and $89.0 \%$ among older mothers. Adolescent mothers were more likely than older mothers to have an infant with preterm delivery, low birthweight, early neonatal death, and birth defects. Adolescent mothers were also late attending antenatal care and late initiating antiretroviral therapy, which has the potential of increasing the risk of mother-to-child HIV transmission. Adolescent pregnancies were also associated with an increased risk of gastroschisis when compared to older mothers.

In conclusion, this study found that adolescent mothers had an increased risk for several adverse birth outcomes compared to older mothers. Research on the potential underlying causes or mechanisms for these adverse outcomes among adolescent pregnancies is necessary to identify possible interventions.

\section{Introduction}

Pregnancies among 15-19 year old females account for 16 million (11\%) births worldwide yet they contribute to $23 \%$ of the maternal disease burden attributed to pregnancy and childbirth.[1, 2] The highest prevalence of adolescent pregnancy is found in the sub-Saharan African region, with birth rates of 101 births per 1,000 females aged 15-19 years in 2018, higher than the global adolescent birth rate of 44 per 1,000.[3] Uganda has one of the youngest populations in sub-Saharan Africa, with children and adolescents 12-19 years constituting more than half (55\%) of the population in 2014,[4] and one of the highest adolescent pregnancy rates (25\%) in sub-Saharan Africa.[5] Despite a decline in the fertility rate in Uganda from 6.9 in 2000 to 5.4 in 2016, and an increase in the use of modern contraception from $18 \%$ in 2000 to $35 \%$ in 2016, adolescent pregnancy remains a challenge with $7.6 \%$ of adolescents having access to contraceptives. [5]

Adolescent births are associated with higher risk of adverse birth outcomes such as preterm birth, low birthweight (LBW), early neonatal deaths (ENND), and birth defects. [1, 6-12] However, few studies on birth outcomes among adolescents have been conducted in developing countries of sub-Saharan Africa, and available data is based on studies with small sample sizes. [13]

We aimed to compare the occurrence of adverse birth outcomes (preterm birth, LBW, and ENND) and major external birth defects among adolescent mothers (12-19 years) to older mothers (20-34 years).

\section{Methods}


We analyzed data collected between August 2015 and December 2018 from a birth defects surveillance system implemented in four major hospitals in Kampala, Uganda. These hospitals have approximately 50,000 births annually, which make up more than $55 \%$ of all births in Kampala. The details of the birth defects surveillance system are described elsewhere. [14] Briefly, this surveillance system collected information from hospital records including: demographic (maternal age, delivery site), maternal health (maternal HIV status, obstetric history), and birth outcome (mode of delivery, pregnancy outcome, infant sex, gestational age, and infant examinations). Information on maternal HIV status and antiretroviral therapy was obtained from antenatal records and inpatient hospital records. Information on all live births, stillbirths, and spontaneous abortions was collected between the time of birth and discharge which usually occurs within the first 24 hours after delivery. [14] Infants born outside the four hospitals and uninformative macerated stillbirths were not included in the surveillance system.

We defined adolescent births as those occurring in women 12-19 years of age at delivery and births among older women as those occurring in women 20-34 years of age at delivery. There were no births to women younger than 12 years of age. We defined gestational age as the interval between the date of delivery and the last menstrual period (LMP) in completed weeks; if the LMP was unknown or missing, a clinical estimate of gestational age was used, such as estimates from fundal height or abdominal ultrasound. We defined preterm delivery as live births occurring at gestations of less than 37 weeks. Low birth weight (LBW) was defined as an infant weighing less than 2,500 $\mathrm{g}$ measured within 24 hours after birth using digital scales among term ( $\geq 37$ weeks) live births. Early neonatal death (ENND) was defined as death among live neonates born at term during the first 48 hours or before the mother was discharged from the hospital. Stillbirth was defined as a baby born with no signs of life at or after 28 weeks' gestation, while a spontaneous abortion was defined as fetal death at less than 28 weeks' gestation. Birth defects were confirmed through bedside examination by a physician and review of photographs, narrative descriptions, and or drawings by a birth defects expert who verified or reassigned the diagnosis code. Details of the birth defect ascertainment and classification have been described previously. [14]

Data were analyzed using STATA version 15 statistical software (StataCorp. 2017. College Station, TX: StataCorp LLC). Descriptive statistics of maternal and infant characteristics by maternal age group were calculated as frequencies and percentages, and the differences between proportions were tested with Pearson's chi-square test.

We used multivariable logistic regression analysis to estimate crude and adjusted odds ratios (cORs and aORs, respectively) along with their 95\% confidence intervals (Cls) for the associations between adolescent pregnancies and adverse birth outcomes with the 20-34 years age group as the reference. Separate multivariable logistic regression models were generated for preterm birth, LBW, ENND, each major birth defect category (neural tube defects, malformations of the eyes and ears, orofacial clefts, and malformations of the musculoskeletal system), and each of the 16 specific birth defects. The analysis of preterm birth was limited to live births; while that of LBW and ENND was limited to term live births. The following covariates were considered for adjustment: parity, mode of delivery, singleton/multiple delivery, number of antenatal visits, and initiation time of prenatal care. The specific covariates used in each model were selected based on previous studies, [6, 15-18] and excluded possible collider variables.

Birth prevalence per 10,000 births for seven categories of major external birth defects and 16 specific birth defects[14] was calculated by maternal age group along with 95\% Wilson's Cls.

\section{Results}

A total of 96,938 pregnancies with 100,189 births among mothers 12 to 34 years of age were captured. Of these, 11,028 (11.1\%) births were among adolescent mothers and 89,161 (89.0\%) births were among older mothers. Table 1 shows the maternal and infant characteristics by age group. The proportion of mothers with HIV infection was significantly lower in adolescent mothers $(4.5 \%$ vs $8.9 \%$, $p<0.001)$ but a significantly higher proportion of HIV-infected adolescents had not initiated on antiretroviral therapy (ART) by the time of delivery compared to older mothers ( $8.8 \%$ vs $4.4 \%$, p $<0.001)$. HIV infected adolescent mothers had a significantly higher proportion initiated on ART after conception compared to older mothers. $(69.6 \%$ vs $45.2 \%$, p<0.001). Adolescent mothers were less likely to have attended any antenatal care (ANC) $(96.5 \%$ vs $97.9 \%, p<0.001)$, attended the recommended four or more antenatal visits (34.9\% vs $44.2 \%, p<0.001)$, [19] or attended the first antenatal visit within the first trimester ( $6.6 \%$ vs $8.0 \%, \mathrm{p}<0.001)$ compared to older mothers. Also, adolescents were more likely to have been referred from another health center for delivery, contributing $70 \%$ of referred women. Adolescent mothers were also more likely than older mothers to be primipara (83.7\% vs $27.6 \%$, $p<0.001)$, have vaginal deliveries (77.8\% vs $67.5 \%, p<0.001)$, and have singleton deliveries $(95.4 \%$ vs $93.1 \%$, $\mathrm{p}<0.001)$.

Table 1. Maternal and reproductive characteristics of adolescent mothers 12-19 and older mothers 20-34 years of age 


\begin{tabular}{|c|c|c|c|c|}
\hline & \multirow[t]{2}{*}{ Total, n (\%) } & \multicolumn{3}{|c|}{ Maternal age, $n(\%)$} \\
\hline & & $12-19$ years & 20-34 years & p-Value \\
\hline No. of births & $100189(100)$ & $11028(11.0)$ & $89161(89.0)$ & - \\
\hline No. of mothers & $96938(100)$ & $10783(11.1)$ & $86155(88.9)$ & - \\
\hline \multicolumn{5}{|l|}{ Maternal age } \\
\hline Median; Inter-quartile range (IQR) & $25 ; 22-29$ & $18 ; 18-19$ & $26 ; 23-29$ & - \\
\hline \multicolumn{5}{|l|}{ Hospital $^{b}$} \\
\hline Lubaga & $6410(6.4)$ & $134(1.2)$ & $6276(7.0)$ & $<0.001$ \\
\hline Mengo & 7905 (7.9) & $111(1.0)$ & 7794 (8.7) & \\
\hline Nsambya & $7531(7.5)$ & $99(0.9)$ & $7432(8.3)$ & \\
\hline Mulago national referral & $78343(78.2)$ & $10684(96.9)$ & $67659(75.9)$ & \\
\hline \multicolumn{5}{|l|}{ Maternal HIV Status ${ }^{a}$} \\
\hline Positive & $8167(8.4)$ & $480(4.5)$ & $7687(8.9)$ & $<0.001$ \\
\hline Negative & $88631(91.4)$ & $10282(95.3)$ & $78349(91.0)$ & \\
\hline Unknown & $140(0.1)$ & $21(0.2)$ & $119(0.1)$ & \\
\hline \multicolumn{5}{|c|}{ Maternal antiretroviral therapy (ART) at delivery ${ }^{\beta}$} \\
\hline Yes & $7786(95.3)$ & $438(91.3)$ & $7348(95.6)$ & $<0.001$ \\
\hline No & $381(4.7)$ & $42(8.8)$ & $339(4.4)$ & \\
\hline \multicolumn{5}{|c|}{ Maternal timing of initiation on ART $\Pi$} \\
\hline Before Conception & $4161(53.4)$ & $133(30.4)$ & $4028(54.8)$ & $<0.001$ \\
\hline After Conception & $3625(46.6)$ & $305(69.6)$ & $3320(45.2)$ & \\
\hline \multicolumn{5}{|c|}{ Mother referred from other health center ${ }^{a}$} \\
\hline Yes & $44700(46.1)$ & $7541(69.9)$ & $37159(43.1)$ & $<0.001$ \\
\hline No & $52238(53.9)$ & $3242(30.1)$ & $48996(56.9)$ & \\
\hline \multicolumn{5}{|l|}{ Maternal parity ${ }^{a}$} \\
\hline Primipara (1) & $32765(33.8)$ & $9023(83.7)$ & $23742(27.6)$ & $<0.001$ \\
\hline Multipara $(\geq 2)$ & $64173(66.2)$ & $1760(16.3)$ & $62413(72.4)$ & \\
\hline \multicolumn{5}{|l|}{ Mode of delivery ${ }^{b}$} \\
\hline Vaginal & $68756(68.6)$ & $8575(77.8)$ & $60181(67.5)$ & $<0.001$ \\
\hline Caesarean section & $31433(31.4)$ & $2453(22.2)$ & $28980(32.5)$ & \\
\hline \multicolumn{5}{|l|}{ Singleton/multiple deliveries ${ }^{b}$} \\
\hline Singleton & $93548(93.4)$ & $10516(95.4)$ & $83032(93.1)$ & $<0.001$ \\
\hline Multiple & $6641(6.6)$ & $512(4.6)$ & $6129(6.9)$ & \\
\hline \multicolumn{5}{|l|}{ Received antenatal care (maternal) $^{a}$} \\
\hline Yes & $94734(97.7)$ & $10403(96.5)$ & $84331(97.9)$ & $<0.001$ \\
\hline No & $2204(2.3)$ & $380(3.5)$ & $1824(2.1)$ & \\
\hline \multicolumn{5}{|c|}{ Timing of first antenatal care (ANC) visit ${ }^{a, \xi}$} \\
\hline ANC within 1st Trimester & $6446(7.9)$ & $580(6.6)$ & $5866(8.0)$ & $<0.001$ \\
\hline
\end{tabular}




\begin{tabular}{|c|c|c|c|c|}
\hline ANC within 2nd Trimester & $36783(44.9)$ & $3976(45.3)$ & $32807(44.8)$ & \\
\hline ANC within 3rd Trimester & $38696(47.2)$ & $4217(48.1)$ & $34479(47.1)$ & \\
\hline \multicolumn{5}{|l|}{ Number of maternal antenatal visits ${ }^{a, \pi}$} \\
\hline No ANC Visit & $2204(2.3)$ & $380(3.5)$ & $1824(2.1)$ & $<0.001$ \\
\hline 1-3 Visits & $52764(54.6)$ & $6626(61.5)$ & $46138(53.7)$ & \\
\hline 4+ Visits & $41731(43.2)$ & $3761(34.9)$ & $37970(44.2)$ & \\
\hline $\begin{array}{l}\text { a Denominator is the number of mothers } \\
{ }^{b} \text { Denominator is the number of births }\end{array}$ & & & & \\
\hline \multicolumn{5}{|c|}{${ }^{\beta}$ Denominator is the number of HIV positive mothers $(n=8,167)$} \\
\hline \multicolumn{5}{|c|}{$\Pi$ Denominator is the number of HIV positive mothers on ART $(n=7,786)$} \\
\hline \multicolumn{5}{|l|}{$\xi 10,605$ mothers missing date of first ANC visit } \\
\hline${ }^{\pi} 239$ mothers missing the number of ANC visits & & & & \\
\hline
\end{tabular}

Adolescent mothers were significantly more likely than older mothers to have preterm (<37 weeks) live births (aOR: 1.14; $95 \%$ Cl: $1.06-1.23$, $\mathrm{p}=0.001$ ), (Table 2). Among live births delivered at term, adolescents were at higher risk of delivering a LBW infant (aOR: 1.46; 95\% Cl: 1.341.59; $p<0.001$ ) and early neonatal death (aOR: 1.58; 95\% Cl: 1.23-2.02; $p<0.001)$ (Table 2). Adolescents were more likely to have a spontaneous abortion (cOR:1.37 95\% Cl: 1.19-1.58; p<0.001), but after adjusting for confounders the association was not statistically significant (aOR: 0.94 ; 95\% Cl: 0.83-1.11) (Table 2). 
Table 2: Comparison of perinatal outcomes between adolescent mothers 12-19 and older mothers 20-34 years of age

Total, $\mathrm{n}(\%) \quad$ Maternal age, $\mathrm{n}(\%)$

12-19 Years 20-34 Years $\operatorname{cOR}(95 \% \mathrm{Cl})$ * $\underset{c}{\mathrm{p} \text {-Value }}$ aOR $(95 \% \mathrm{Cl})$ * $\underset{d}{\mathrm{p} \text {-value }}$

\section{Gestational age ${ }^{\text {a }}$}

\begin{tabular}{|c|c|c|c|c|c|c|c|}
\hline$<37$ weeks & $8,564(9.0)$ & $1,068(10.2)$ & 7,496 (8.8) & $\begin{array}{l}1.18(1.10- \\
1.26)\end{array}$ & $<0.001$ & $\begin{array}{l}1.14(1.06- \\
1.23)\end{array}$ & 0.001 \\
\hline 37 weeks & $\begin{array}{l}86,839 \\
(91.0)\end{array}$ & 9,358 (89.8) & $\begin{array}{l}77,481 \\
(91.2)\end{array}$ & 1 & & 1 & \\
\hline
\end{tabular}

\section{Birth outcome}

\begin{tabular}{|c|c|c|c|c|c|c|c|}
\hline Live birth & $\begin{array}{l}95,403 \\
(95.2)\end{array}$ & $\begin{array}{l}10,426 \\
(94.5)\end{array}$ & $\begin{array}{l}84,977 \\
(95.3)\end{array}$ & 1 & & 1 & \\
\hline Stillbirth & $3,102(3.1)$ & 359 (3.3) & $2,743(3.1)$ & $\begin{array}{l}1.07(0.95- \\
1.19)\end{array}$ & 0.258 & $\begin{array}{l}1.08(0.95- \\
1.22)\end{array}$ & 0.230 \\
\hline Spontaneous Abortion & $1,684(1.7)$ & $243(2.2)$ & $1,441(1.6)$ & $\begin{array}{l}1.37(1.19- \\
1.58)\end{array}$ & $<0.001$ & $\begin{array}{l}0.94(0.83- \\
1.11)\end{array}$ & 0.488 \\
\hline
\end{tabular}

Infant birth weight ( 37 weeks)

\begin{tabular}{lllllll}
$<2500 \mathrm{~g}$ & $6,572(7.6)$ & $986(10.5)$ & $5,586(7.2)$ & $\begin{array}{l}1.51(1.41- \\
1.63)\end{array}$ & $<0.001$ & $\begin{array}{l}1.46(1.34- \\
1.59)\end{array}$ \\
\hline $2500 \mathrm{~g}$ & $\begin{array}{l}80,267 \\
(92.4)\end{array}$ & $8,372(89.5)$ & $\begin{array}{l}71,895 \\
(92.8)\end{array}$ & 1 & 1 \\
\hline
\end{tabular}

\section{ENND ( 37 weeks) a, b}

\begin{tabular}{|c|c|c|c|c|c|c|c|}
\hline Yes & $441(0.5)$ & $82(1.0)$ & $359(0.5)$ & $\begin{array}{l}1.96(1.57- \\
2.45)\end{array}$ & $<0.001$ & $\begin{array}{l}1.58(1.23- \\
2.02)\end{array}$ & $<0.001$ \\
\hline No & $\begin{array}{l}82,159 \\
(99.5)\end{array}$ & $8,511(99.0)$ & $\begin{array}{l}73,648 \\
(99.5)\end{array}$ & 1 & & 1 & \\
\hline \multicolumn{8}{|c|}{ Birth defect } \\
\hline No & $\begin{array}{l}99,674 \\
(99.5)\end{array}$ & $\begin{array}{l}10,954 \\
(99.3)\end{array}$ & $\begin{array}{l}88,720 \\
(99.5)\end{array}$ & 1 & & 1 & \\
\hline Yes $*$ & $515(0.5)$ & $74(0.7)$ & $441(0.5)$ & $\begin{array}{l}1.36(1.06- \\
1.74)\end{array}$ & 0.015 & $\begin{array}{l}1.36(1.02- \\
1.80)\end{array}$ & 0.032 \\
\hline
\end{tabular}

a Live births only $(n=95,403)$

b Early neonatal death (ENND); term births $(n=86,839)$

c p-value for cOR

d p-value for aOR

* The cOR $(95 \% \mathrm{Cl})$ and aOR $(95 \% \mathrm{Cl})$ were calculated with $20-34$ years as the reference age group.

Gestational age model was restricted to live births only with adjustment for parity, mode of delivery, singleton/multiple deliveries, and number of antenatal visits.

Birth outcome model was adjusted for parity, mode of delivery and number of antenatal visits.

Early neonatal death model was restricted to full-term infants (gestation $\geq 37$ weeks) and adjusted for parity, mode of delivery and number of antenatal visits.

Birth weight model was restricted to full-term infants (gestation $\geq 37$ weeks) and adjusted for parity, mode of delivery, singleton/multiple deliveries and number of antenatal visits.

Overall birth defect model was adjusted for parity, mode of delivery, singleton/multiple births and number of antenatal visits.

${ }^{¥}$ Newborns with at least one of the sixteen major external birth defects of interest to the study 
Adolescent mothers had a higher prevalence of birth defects (67.1 per 10,000 births, $95 \%$ Cl: $53.5-84.2)$ compared to older mothers (49.7 per 10,000 births, $95 \% \mathrm{Cl}$ : 45.3-54.5). The odds of major external birth defects were higher among adolescents in comparison to older mothers (aOR: 1.36; 95\% Cl: 1.02-1.80; $\mathrm{p}=0.032$ ). Talipes equinovarus (124 were isolated talipes and 26 were part of a neural tube defect sequence) was the most prevalent major external birth defect among adolescent mothers (19.9 per 10,000 births; $95 \%$ Cl: $13.2-30.2)$ while for older mothers, it was hypospadias (22.6 per 10,000 births; $95 \%$ Cl: 18.7-27.4) [Figure 1].

Adolescent mothers were significantly more likely to have an infant born with microcephaly (cOR: $4.04,95 \% \mathrm{Cl}: 1.01-16.17)$ and gastroschisis (cOR: 4.62; 95\% Cl: 1.93-11.02). However, after adjustment for parity and initiation time of prenatal care, only gastroschisis (aOR: $3.20 ; 95 \%$ Cl: 1.12-9.13) remained significantly associated with adolescent pregnancy (Table 3). Musculoskeletal defects (aOR: 1.69; 95\% Cl: 1.15-2.50) and malformations of eyes and ears (aOR: $3.09 ; 95 \% \mathrm{Cl}: 1.01-9.42)$ were also significantly higher among adolescent births compared to those from older mothers (Table 3 ). 


\begin{tabular}{|c|c|c|c|c|c|c|}
\hline \multirow[t]{2}{*}{ ICD-10 RCPCH code ${ }^{a}$} & \multirow[t]{2}{*}{ Birth defects } & \multicolumn{2}{|c|}{ Number of defects } & \multirow[t]{2}{*}{$\operatorname{cOR}(95 \% \mathrm{Cl})$} & \multirow[t]{2}{*}{ aOR $(95 \% \mathrm{Cl})^{d}$} & \multirow{2}{*}{$\begin{array}{l}\mathrm{p}- \\
\text { value }\end{array}$} \\
\hline & & $\begin{array}{l}12-19 \\
\text { years }\end{array}$ & $\begin{array}{l}20-34 \\
\text { years }\end{array}$ & & & \\
\hline \multicolumn{2}{|l|}{$\underset{\star}{\text { Neural tube defects (NTD) }}$} & 9 & 95 & $0.77(0.39-1.52)$ & $0.63(0.27-1.52)$ & 0.311 \\
\hline Q00.0 & Anencephaly & 2 & 27 & $0.60(0.14-2.52)$ & $0.64(0.14-2.90)$ & 0.559 \\
\hline Q00.1 & Craniorachischisis & 0 & 2 & na & na & na \\
\hline Q01.0-Q01.2, Q01.8-Q01.9 & Encephalocele & 4 & 11 & $2.94(0.94-9.24)$ & $1.43(0.27-7.43)$ & 0.673 \\
\hline Q05.0-Q05.9 & Spina bifida & 3 & 56 & $0.43(0.14-1.38)$ & $0.40(0.08-1.67)$ & 0.202 \\
\hline Q02 & Microcephaly & 3 & 6 & $\begin{array}{l}4.04(1.01-16.17) \\
\beta\end{array}$ & $\begin{array}{l}4.54(0.81- \\
25.39)\end{array}$ & 0.085 \\
\hline \multicolumn{2}{|c|}{ Malformations of eyes and ears } & 5 & 28 & $1.44(0.56-3.74)$ & $3.09(1.01-9.42)$ & 0.047 \\
\hline Q11-Q11.1; Q11.2 & $\begin{array}{l}\text { Anophthalmia; } \\
\text { Microphthalmia }\end{array}$ & 3 & 12 & $2.02(0.57-7.16)$ & $\begin{array}{l}3.21(0.71- \\
14.38)\end{array}$ & 0.128 \\
\hline Q16.0; Q17.2 & Anotia; Microtia & 2 & 16 & $1.01(0.23-4.40)$ & $\begin{array}{l}2.94(0.55- \\
15.72)\end{array}$ & 0.206 \\
\hline \multicolumn{2}{|l|}{ Orofacial clefts ${ }^{b}$} & 9 & 51 & $1.43(0.70-2.90)$ & $1.28(0.57-2.91)$ & 0.549 \\
\hline $\begin{array}{l}\text { Q35.1-Q35.9, Q38.5, } \\
\text { Q87.0 }\end{array}$ & Cleft palate & 2 & 13 & $1.24(0.28-5.51)$ & $0.71(0.08-6.12)$ & 0.752 \\
\hline Q36.0, Q36.9 & Cleft lip alone & 3 & 12 & $2.02(0.57-7.16)$ & $\begin{array}{l}2.54(0.59- \\
11.50)\end{array}$ & 0.213 \\
\hline Q37.0-Q37.9 & Cleft lip + palate & 4 & 26 & $1.24(0.43-3.56)$ & $1.09(0.35-3.41)$ & 0.877 \\
\hline Q42.3 & Imperforate anus & 1 & 20 & $0.40(0.05-3.01)$ & $1.06(0.12-9.08)$ & 0.960 \\
\hline Q54.0-Q54.3, Q54.8-Q54.9 & Hypospadias $^{c}$ & 10 & 104 & $0.75(0.39-1.44)$ & $0.63(0.29-1.34)$ & 0.230 \\
\hline \multicolumn{2}{|l|}{ Musculoskeletal system * } & 45 & 214 & $1.70(1.23-2.35)^{\beta}$ & $1.69(1.15-2.50)$ & 0.008 \\
\hline Q66.0, Q66.8 & Talipes equinovarus & 22 & 128 & $1.41(0.89-2.22)$ & $1.33(0.77-2.30)$ & 0.309 \\
\hline Q71.0-Q73.8 & Total limb reduction & 8 & 44 & $1.47(0.69-3.12)$ & $1.75(0.67-4.56)$ & 0.249 \\
\hline Q79.2 & Omphalocele & 8 & 41 & $1.58(0.74-3.37)$ & $2.17(0.92-5.18)$ & 0.078 \\
\hline Q79.3 & Gastroschisis & 8 & 14 & $\begin{array}{l}4.62(1.93-11.02) \\
\beta\end{array}$ & $3.20(1.12-9.13)$ & 0.030 \\
\hline \multicolumn{7}{|c|}{ * Some infants had more than one type of defect in the neural tube defects and musculoskeletal system categories } \\
\hline \multicolumn{7}{|c|}{ b Excluded Q36.1 (medial Cleft lip) } \\
\hline \multicolumn{7}{|c|}{${ }^{\beta}$ Statistically significant at $p<0.05$} \\
\hline \multicolumn{7}{|c|}{ na - Prevalence, cOR, aAOR and $95 \%$ confidence intervals that cannot be calculated } \\
\hline \multicolumn{7}{|c|}{${ }^{c}$ Denominator for males: $N=51,922 ; 12-19$ Years $(n=5,896) ; 20-34$ Years $(n=46,026)$} \\
\hline${ }^{\mathrm{d}}$ Covariates for the birth de & t models: parity and $\mathrm{i}$ & 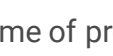 & care & & & \\
\hline
\end{tabular}

\section{Discussion}

In this study, we observed that adolescent mothers were more likely to have an infant with the adverse birth outcome of preterm delivery, LBW, ENND, or a major external birth defect such as gastroschisis as compared to older mothers. Previous studies have also found an increased risk 
for preterm delivery in adolescent pregnancies, $[6,13,15]$ which could be attributable to the maternal-fetal competition for nutrients that arises when pregnancy coincides with continuing or incomplete growth in adolescents.[20]

Our study finds that adolescent mothers were more likely to deliver LBW babies is consistent with results from the Uganda Demographic Health Survey 2011.[21] That survey also identified infants born with LBW to be at increased risk of neonatal death,[22] highlighting the risks associated with LBW in this population. The LBW observed among infants born to adolescent mothers could have been due to factors such as inadequate maternal nutrition, or the related but distinct issue of inadequate weight gain during pregnancy,[16] which were not assessed in our study.

Comparable to findings from a study exploring the impact of early motherhood on neonatal mortality in 45 low and middle-income countries, our study showed that ENNDs in full-term babies occurred more frequently among adolescent mothers.[7] In contrast, a World Health Organization (WHO) multicounty survey across 29 countries in Africa, Asia, Latin America, and the Middle East found that ENND among infants born to adolescent mothers was not significantly different from mothers aged 20-24 years, after controlling for confounders.[6] This difference may be related to restriction in the WHO study to mothers aged 24 years or younger who gave birth to an infant of at least 22 weeks' gestation as compared to mothers $\leq 34$ years in our analysis and the WHO study's classification of ENND as intra-hospital deaths that occurred within 7 days after birth as compared to deaths within 48 hours in our analysis.

Initiation of all pregnant HIV-infected women on ART is required to eliminate mother to child transmission (MTCT) of HIV. We found that a significantly higher proportion of HIV-infected adolescents were not on ART at conception or delivery compared to older women, which is consistent with findings from the Uganda Population-Based HIV Impact Household-based National Survey.[23] The lower prevalence of ART use among HIV-infected adolescents translates to a potential increased risk of MTCT of HIV among adolescents compared to older mothers and the need to strengthen services for this population. [24] Our data showed that adolescents were more likely to have late first ANC attendance and inadequate ANC visits, with late initiation on ART potentially reducing their time to protect against MTCT. Some commonly considered factors for a lack of or late ANC attendance among adolescents in low-and middle-income countries were low mass media exposure on ANC, low-level education, and wealth status.[25] A facility-based survey in South Africa also found that HIV-positive adolescent mothers were significantly less likely to be on any ART compared with adult mothers.[24] Further analysis is needed to determine if the lower prevalence of ART use among HIV-infected adolescents was a result of factors such as late or insufficient ANC or relatively later HIV diagnosis during pregnancy or at birth.

In this study, adolescent mothers were more likely to deliver a newborn with a birth defect when compared with older mothers. Although the number for some birth defects were small in our study, our findings suggest that(32) gastroschisis was significantly higher among adolescent mothers when compared to older mothers, as reported by other studies.[26, 27] While comparing gastroschisis to other congenital anomalies, Given, et al. (2017) reported sexually transmitted infections, and continuation of oral contraceptives in early pregnancy, as preventable risk factors.[28] We were not able to assess these factors in this study. Our study also found that adolescent mothers were associated with increased odds of musculoskeletal defects as well as malformations of eyes and ears combined. Chen, et al. (2007) found increased odds of musculoskeletal defects but from some different specific defects within the category.[26]

This study's strengths include a large sample size, which made it possible to assess the association between adolescent pregnancy and possible risk factors of adverse birth outcomes. Also, physical examination of newborns by trained staff and several levels of external birth defect review ensured consistent birth defect classification and coding.

\section{STUDY LIMITATIONS}

Study limitations include surveillance activities being conducted at four major urban hospitals located in the capital city and is not representative of adolescent pregnancies nationally.[5] Secondly, because infants were not followed post-discharge, we captured only ENND that occurred within 48 hours of birth. The standard definition of ENND is death within seven days of delivery so infants that died between discharge and seven days of life was not accounted for, resulting in a possible underestimation of ENND.

Finally, this study did not control for several risk factors known to influence reproductive health outcomes such as social-economic status, level of education, tobacco smoking, alcohol drinking, maternal nutrition, and the use of folic acid since this information was not captured in the surveillance. $[18,29]$

\section{Conclusion}

Our study is one of the few studies reporting adverse birth outcomes among adolescent women in Sub-Saharan Africa.[30] Our results corroborate previous findings on birth outcomes and demonstrate that adolescent pregnancy is a risk factor for several neonatal adverse birth 
outcomes. With the growing population and high rates of adolescent pregnancy, the number of adverse birth outcomes is likely to increase and thereby remain a key public health concern.[5]

Further research on individual, socio-cultural, environmental, economic, and health service-related factors are required to identify practicable and scalable measures to decrease adolescent pregnancy and to identify and reduce obstacles that discourage the use of qualified antenatal services, that would prevent or reduce adverse reproductive outcomes such as neonatal deaths, low birth weight, mother to child transmission of HIV and birth defects. The establishment of dedicated adolescent-friendly antenatal care programs would help improve neonatal and adolescent health,[31] and, better understand associated risk factors and the impact of younger maternal age on pregnancy outcomes. It is critical to monitor trends in birth outcomes and prevalence of major external birth defects across age groups to inform health-care policies and to plan for needed services among the affected population. Research on the potential underlying causes or mechanisms for these adverse outcomes among adolescent pregnancies is necessary to identify possible interventions.

\section{Abbreviations}

cOR: Crudes Odds Ratio; aORs: Adjusted odds ratios; Cl: Confidence Intervals; LBW: low birthweight; ENND: Early Neonatal Deaths; MTCT: Mother to Child Transmission; ANC: Antenatal care; ART: Antiretroviral therapy; WHO: World Health Organization; CDC: Centers for Diseases Control and Prevention; HIV: Human immunodeficiency virus; LMP: Last menstrual period; US: United States;

\section{Declarations}

\section{ETHICS APPROVAL AND CONSENT TO PARTICIPATE}

This surveillance study was approved by the Uganda National Council of Science and Technology (UNCST), (Ref: HS 1693); the Joint Clinical Research Centre institutional review board/Ethics committee (JCRC IRB), and the US Centers for Disease Control and Prevention Institutional Review Board (CDC IRB) (protocol \# 6606.0).

Consent to participate in the surveillance was waived by both IRBs (JCRC and CDC) because the surveillance involves no more than minimal risk to the participants. However, IRB-approved written informed consent was obtained for photographs of newborns with birth defects from their mothers or legal guardians.

\section{FUNDING}

This research has been supported by the President's Emergency Plan for AIDS Relief through the United States Centers for Disease Control and Prevention under the terms of grants number: 1U10GH000487, 5U01GH000487, and 5U01GH002171.

\section{DISCLAIMER}

The findings and conclusions in this report are those of the authors and do not necessarily represent the official position of the funding agencies.

\section{CONSENT FOR PUBLICATION}

Not applicable

\section{AVAILABILITY OF DATA AND MATERIALS}

Not applicable

\section{COMPETING INTERESTS}

The authors declare that they have no competing interests.

\section{DISCLOSURE}

The authors report no conflicts of interest in this work. 


\section{AUTHOR CONTRIBUTIONS}

RS: took the lead in writing of the manuscript and is accountable for all aspects of the work in ensuring that questions related to the accuracy or integrity of any part of the work are appropriately investigated and resolved.

LBM, PM, DMM, SCT, DW, MRA, and DV: Substantial contributions to the conception or design of the work; or the acquisition, analysis, or interpretation of data for the work. They were involved in drafting the manuscript and revising it critically for important intellectual content.

DK, JNM, JN, EN, DBM, and JB: were involved in drafting the manuscript and revising it critically for important intellectual content.

All authors: Approved the final manuscript version submitted.

\section{ACKNOWLEDGMENTS}

The authors wish to thank all staff of the Birth Defects Surveillance study, and all management and staff of Mulago Referral Hospital, Mengo Hospital, St. Francis Hospital Nsambya, and Uganda Martyrs Hospital Lubaga who made the surveillance possible at their hospital. We also thank the management and administration of Makerere University-Johns Hopkins University Research Collaboration for all their support.

\section{References}

1. WHO. World Health Organisation. Adolescent pregnancy 2014 [Available from: https://apps.who.int/iris/rest/bitstreams/514257/retrieve accessed 8/17/2018.

2. WHO. Why is giving special attention to adolescents important for achieving Millennium Development Goal 5 ? 2008 [Available from: https://www.who.int/maternal_child_adolescent/events/2008/mdg5/adolescent_preg.pdf.

3. United Nations. The Sustainable Development Goals Report United Nations, New York: United Nations; [Available from: https://unstats.un.org/sdgs/files/report/2018/TheSustainableDevelopmentGoalsReport2018-EN.pdf accessed 1/20/2020.

4. Uganda Bureau of Statistics. Statistical Abstract: Uganda Bureau of Statistics; 2017 [341]. Available from: https://www.ubos.org/wpcontent/uploads/publications/03_20182017_Statistical_Abstract.pdf accessed 11/2/2018.

5. Uganda Bureau of Statistcs (UBOS) and ICF. Uganda Demographic and Health Survey 2016. Kampala Uganda: UBOS and Calverton, Maryland: ICF International Inc; 2017.

6. Ganchimeg T, Ota E, Morisaki N, Laopaiboon M, Lumbiganon P, Zhang J, Yamdamsuren B, Temmerman M, Say L, Tuncalp O et al: Pregnancy and childbirth outcomes among adolescent mothers: a World Health Organization multicountry study. BJOG 2014,121 Suppl 1:40-48.

7. Neal S, Channon AA, Chintsanya J: The impact of young maternal age at birth on neonatal mortality: Evidence from 45 low and middle income countries. PLoS One 2018, 13(5):e0195731.

8. Althabe F, Moore JL, Gibbons L, Berrueta M, Goudar SS, Chomba E, Derman RJ, Patel A, Saleem S, Pasha O et al: Adverse maternal and perinatal outcomes in adolescent pregnancies: The Global Network's Maternal Newborn Health Registry study. Reprod Health 2015,12 Suppl 2:S8.

9. Kongnyuy EJ, Nana PN, Fomulu N, Wiysonge SC, Kouam L, Doh AS: Adverse Perinatal Outcomes of Adolescent Pregnancies in Cameroon. Maternal and Child Health Journal 2008, 12(2):149-154.

10. Gortzak-Uzan L, Hallak M, Press F, Katz M, Shoham-Vardi I: Teenage pregnancy: risk factors for adverse perinatal outcome. J Matern Fetal Med 2001, 10(6):393-397.

11. Igwegbe AO, Udigwe GO: Teenage pregnancy: still an obstetric risk. J Obstet Gynaeco/2001, 21(5):478-481.

12. Olausson PO, Cnattingius S, Haglund B: Teenage pregnancies and risk of late fetal death and infant mortality. Br J Obstet Gynaecol 1999 , 106(2):116-121.

13. Gronvik T, Fossgard Sandoy I: Complications associated with adolescent childbearing in Sub-Saharan Africa: A systematic literature review and meta-analysis. PLoS One 2018, 13(9):e0204327.

14. Mumpe-Mwanja D, Barlow-Mosha L, Williamson D, Valencia D, Serunjogi R, Kakande A, Namale-Matovu J, Nankunda J, Birabwa-Male D, Okwero MA et al: A hospital-based birth defects surveillance system in Kampala, Uganda. BMC Pregnancy Childbirth 2019, 19(1):372.

15. Mombo-Ngoma G, Mackanga JR, González R, Ouedraogo S, Kakolwa MA, Manego RZ, Basra A, Rupérez M, Cot M, Kabanywany AM et al: Young adolescent girls are at high risk for adverse pregnancy outcomes in sub-Saharan Africa: an observational multicountry study. BMJ open 2016, 6(6):e011783.

16. Kang G, Lim JY, Kale AS, Lee LY: Adverse effects of young maternal age on neonatal outcomes. Singapore Med J 2015, 56(3):157-163. 
17. Duong HT, Hoyt AT, Carmichael SL, Gilboa SM, Canfield MA, Case A, McNeese ML, Waller DK, the National Birth Defects Prevention S: Is Maternal Parity an Independent Risk Factor for Birth Defects? Birth defects research Part A, Clinical and molecular teratology 2012, 94(4):230-236.

18. Gill SK, Broussard C, Devine O, Green RF, Rasmussen SA, Reefhuis J, The National Birth Defects Prevention S: Association between Maternal Age and Birth Defects of Unknown Etiology - United States, 1997-2007. Birth defects research Part A, Clinical and molecular teratology 2012, 94(12):1010-1018.

19. Ministry of Health U. Uganda Clinical Guidelines 2016: Ministry of Health Uganda; 2016 [1118]. Available from: http://health.go.ug/sites/default/files/Uganda\%20Clinical\%20Guidelines\%202016_FINAL.pdf accessed 11/2/2018.

20. Jacqueline MW: Competition for nutrients in pregnant adolescents: consequences for maternal, conceptus and offspring endocrine systems. J Endocrinol 2019, 242(1):T1-T19.

21. Uganda Bureau of Statistics (UBOS) and ICF International Inc. Uganda Demographic and Health Survey 2011. Kampala Uganda: UBOS and Calverton, Maryland: ICF International Inc; 2012.

22. Arunda MO, Agardh A, Asamoah BO: Survival of low birthweight neonates in Uganda: analysis of progress between 1995 and 2011 . BMC Pregnancy Childbirth 2018, 18(1):189.

23. Ministry of Health, Uganda. Uganda Population-based HIV Impact Assessment (UPHIA) 2016-2017: Final Report. Kampala: Ministry of Health; July, 2019 [Available from: https://phia.icap.columbia.edu/wpcontent/uploads/2019/07/UPHIA_Final_Report_Revise_07.11.2019_Final_for-web.pdf accessed 2/24/2020.

24. Ramraj T, Jackson D, Dinh TH, Olorunju S, Lombard C, Sherman G, Puren A, Ramokolo V, Noveve N, Singh Y et al: Adolescent Access to Care and Risk of Early Mother-to-Child HIV Transmission. J Adolesc Health 2018, 62(4):434-443.

25. Banke-Thomas OE, Banke-Thomas AO, Ameh CA: Factors influencing utilisation of maternal health services by adolescent mothers in Lowand middle-income countries: a systematic review. BMC Pregnancy Childbirth 2017, 17(1):65.

26. Chen XK, Wen SW, Fleming N, Yang Q, Walker MC: Teenage pregnancy and congenital anomalies: which system is vulnerable? Hum Reprod 2007, 22(6):1730-1735.

27. Reefhuis J, Honein MA: Maternal age and non-chromosomal birth defects, Atlanta-1968-2000: teenager or thirty-something, who is at risk? Birth Defects Res A Clin Mol Teratol 2004, 70(9):572-579.

28. Given JE, Loane M, Garne E, Nelen V, Barisic I, Randrianaivo H, Khoshnood B, Wiesel A, Rissmann A, Lynch C et al: Gastroschisis in Europe A Case-malformed-Control Study of Medication and Maternal Illness during Pregnancy as Risk Factors. Paediatr Perinat Epidemiol 2017, 31(6):549-559.

29. Tinker SC, Gilboa S, Reefhuis J, Jenkins MM, Schaeffer M, Moore CA: Challenges in Studying Modifiable Risk Factors for Birth Defects. Current epidemiology reports 2015, 2(1):23-30.

30. Ajibola G, Zash R, Shapiro RL, Batlang O, Botebele K, Bennett K, Chilisa F, Widenfelt EV, Makhema J, Lockman S et al: Detecting congenital malformations - Lessons learned from the Mpepu study, Botswana. PLoS One 2017, 12(3):e0173800.

31. WHO. Making health services adolescent friendly: developing national quality standards for adolescent friendly health services 2012 [Available from: https://apps.who.int/iris/bitstream/handle/10665/75217/9789241503594_eng.pdf;jsessionid=6391680A79868E5D0FAB89144F3466DF? sequence $=1$ accessed 2/15/2020.

\section{Figures}




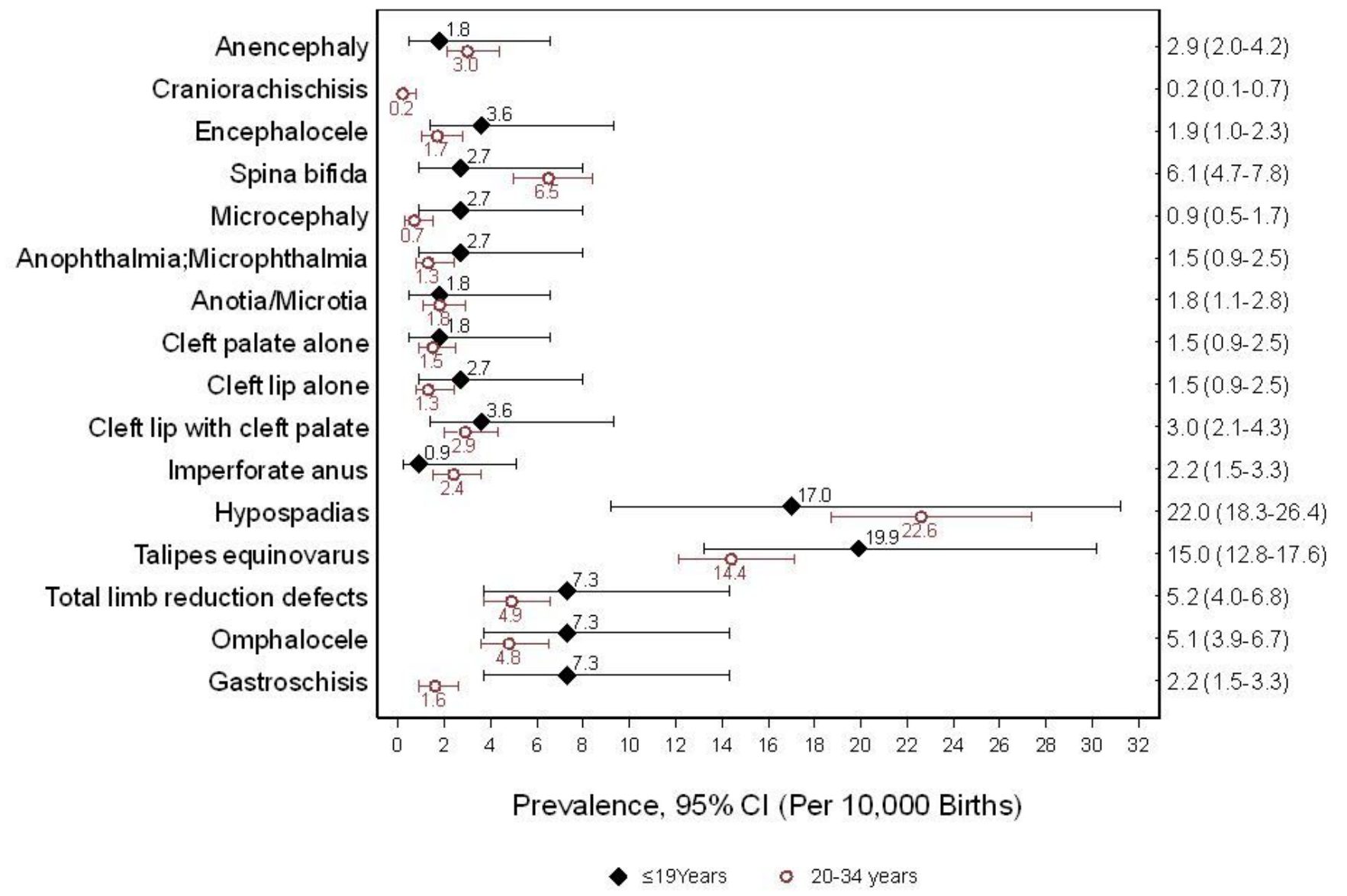

Figure 1

Birth Prevalence per 10,000 births, $95 \%$ Cl of Major External Birth Defects, Kampala, Uganda 